\title{
A scientific note on food alert in Bombus transversalis
}

\author{
Anna DornHAUS ${ }^{\mathrm{a} *}$, Sydney CAMERON ${ }^{\mathrm{b}}$ \\ ${ }^{a}$ Department of Behavioral Physiology and Sociobiology, University of Würzburg, Germany \\ ${ }^{\mathrm{b}}$ Department of Entomology, University of Illinois at Urbana-Champaign, USA
}

(Received 28 March 2002; revised 20 June 2002; accepted 24 June 2002)

bumble bee / communication / foraging / evolution / recruitment in social bees

\section{INTRODUCTION}

Bumble bees (Bombini), stingless bees (Meliponini) and honey bees (Apini), the three major groups of eusocial bees, have very different systems of organizing colony foraging activity, sometimes involving sophisticated mechanisms of recruitment. Honey bees, as the most well known example, perform "waggle dances", highly stereotyped motor patterns, which contain information about coordinates and properties of newly discovered food sources (von Frisch, 1967). In the stingless bees (Meliponini), mechanisms and information content of communication about food sources vary among species from mere alerting systems (no communication of location, only of presence of food sources) to, at the other extreme, communication about location and distance of a food source via scent marks and acoustic signals (Lindauer and Kerr, 1960; Nieh, 1998). In bumble bees, an alerting system which involves communicating presence and odor, but not location of food sources, was found in Bombus terrestris L. (Dornhaus and Chittka, 1999, 2001). However, before concluding that this alerting system is a plesiomorphic character retained in the bumble bees and not solely an invention of $B$. terrestris, its presence in other bumble bees should be demonstrated. This is what we report here.

We examined recruitment behavior of the Amazonian bumble bee, Bombus transversalis (Olivier). This is one of the few bumble bee species adapted to living in the wet tropics (Cameron et al., 1999, Taylor and Cameron, in press). As B. transversalis is in the subgenus Fervidobombus, it is only distantly related to B. terrestris (Williams, 1994). If the same alerting effect can be found in $B$. transversalis as in B. terrestris, that would suggest that an alerting mechanism could be broadly distributed across bumble bees.

\section{EXPERIMENTS}

Two colonies of $B$. transversalis were located in tropical lowland rain forest in the Tambopata river area in southern Peru $\left(12^{\circ} 49^{\prime}\right.$ S, $69^{\circ} 24^{\prime}$ W) during late dry season (Oct. 2001). Colonies were excavated and transferred to wooden nest boxes $(30 \mathrm{~cm} \times 30 \mathrm{~cm} \times 15 \mathrm{~cm}$, with transparent plexiglas cover). Both colonies had begun to produce young queens and males; one was queenless. The queenless colony contained approximately 60 workers, the queenright colony approx. 200 workers; both contained brood.

Experimental methods for testing for alerting were taken from Dornhaus and Chittka (1999). The nest box was connected to two flight arenas $(30 \mathrm{~cm} \times 30 \mathrm{~cm} \times 30 \mathrm{~cm})$ using a Y-shaped plexiglas tube. All bees had access to one of the arenas whereas into the other arena only one, individually marked forager was allowed to enter. The experiment was run 12 times with different bees as marked foragers. Each experimental run consisted of a control and an experimental phase. During the control phase, no food was available to the bees. Their activity was measured by counting the number of bees leaving the nest box per 5-min interval. At the start of the experimental phase, a feeder filled with $2 \mathrm{M}$ unscented sugar solution was set up in the arena to which only the marked forager had access. Thus the forager, who collected sugar solution on several trips during the experimental phase, had information that a food source was present, but the other bees did not, except for information they might get, directly or indirectly, from the forager. Any change in activity between control and experimental phase would show a transfer of information. Indeed such a change in activity takes place: in $B$. transversalis, the activity during the second half of the experimental phase was significantly higher than during the control phase (median activity

\footnotetext{
* Correspondence and reprints

E-mail: a.dornhaus@bristol.ac.uk

Present address: School of Biological Sciences, University of Bristol, Woodland Road, Bristol BS8 1UG (UK).
} 


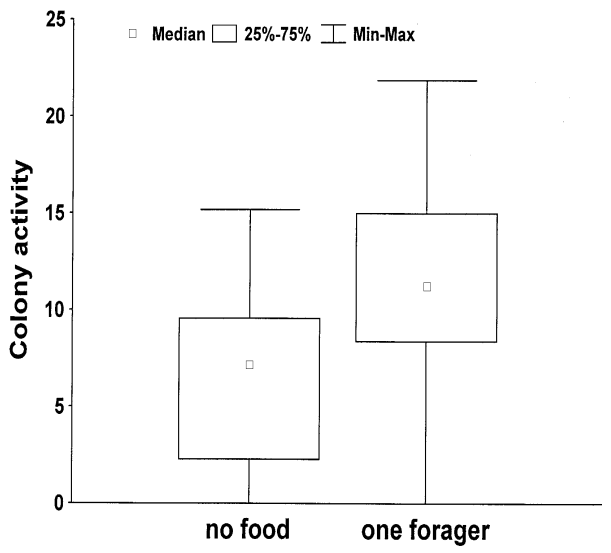

Figure 1. Colony activity, measured as number of bees leaving the nest per 5-min interval not including the trips by the marked forager, increased significantly when the marked forager was allowed to start foraging ( $\mathrm{n}=12$ experimental runs).

increased from 7.2 to 11.3 bees leaving per 5 min interval, $P<0.01, \mathrm{n}=12$ experiments, WilcoxonTest; Fig. 1). This is the same reaction as that shown in $B$. terrestris colonies (Dornhaus and Chittka, 1999).

\section{CONCLUSION}

Since both $B$. transversalis and $B$. terrestris thus possess an alerting mechanism, it is possible that this is a widespread trait in the bumble bee group, although more data from other species are needed to verify this conclusion. Indeed alerting signals, in the form of conspicuous running and, often, sound production as a means of regulating colony foraging activity, may have existed early on in the evolution of the eusocial bees, since they are present not only in bumble bees (Oeynhausen and Kirchner, 2001; Dornhaus and Chittka, 2001), but also in all studied species of stingless bees (Lindauer and Kerr, 1960; Wille, 1983). Thus simple alerting as seen in the bumble bees and stingless bees may have given rise to the more sophisticated communication systems present in some of the other stingless bees today.

\section{ACKNOWLEDGMENTS}

We thank C. Rasmussen and S. Ramírez for field assistance, and the staff at Picaflor Research Station (especially L. Hanna) and Tambopata Jungle Lodge for logistical support. This work was supported by National Science Foundation (\# IBN-9973447) and USDA (\# 2002-35302-11553) grants to S.A.C. and a DFG grant SFB 554, project B5 to L. Chittka.

\section{Note scientifique sur l'avertissement de nourri- ture chez Bombus transversalis.}

Eine wissenschaftliche Notiz zur Futteralarmierung bei Bombus transversalis.

\section{REFERENCES}

Cameron S.A., Whitfield J.B., Cohen M., Thorp N. (1999) Novel use of walking trails by the Amazonian bumble bee, Bombus transversalis (Hymenoptera: Apidae), in: Byers G.W., Hagen R.H., Brooks R.W. (Eds.), Entomological contributions in memory of Byron A. Alexander, Univ. Kansas Nat. Hist. Mus. Spec. Public. No. 24, pp. 187-193.

Dornhaus A., Chittka L. (1999) Evolutionary origins of bee dances, Nature 401, 38.

Dornhaus A., Chittka L. (2001) Food alert in bumblebees (Bombus terrestris): possible mechanisms and evolutionary implications, Behav. Ecol. Sociobiol. 50, 570-576.

Frisch K. von (1967) The dance language and orientation of bees, Harvard Univ. Press, Cambridge.

Lindauer M.,. Kerr W.E. (1960) Communication between the workers of stingless bees, Bee World 41, 29-71.

Nieh J.C. (1998) The food recruitment dance of the stingless bee, Melipona panamica, Behav. Ecol. Sociobiol. 43, 133-145.

Oeynhausen A., Kirchner W. (2001) Vibrational signals of foraging bumblebees (Bombus terrestris) in the nest, Proc. meeting of the European Sections of IUSSI, Berlin, 25-29 Sept. 2001, 31.

Taylor O.M., Cameron S.A., Nest architecture of the Amazonian bumble bee (Hymenoptera: Apidae), Apidologie (in press).

Wille A. (1983) Biology of the stingless bees, Annu. Rev. Entomol. 28, 41-64.

Williams P.H. (1994) Phylogenetic relationships among bumble bees (Bombus Latr.): a reappraisal of morphological evidence, Syst. Entomol. 19, 327-344. 